\title{
PRÁTICA DE ENSINO E ESTÁGIO SUPERVISIONADO NO PROCESSO DE FORMAÇÃO DOS PROFESSORES
}

\author{
TEACHING PRACTICE AND SUPERVISED INTERNSHIP \\ IN THE TEACHER TRAINING PROCESS
}

Rosana Cássia Rodrigues Andrade ${ }^{1}$

\section{RESUMO}

Nesta pesquisa, analiso as produções acadêmicas apresentadas no Encontro Nacional de Didática e Prática de Ensino ocorrido, no período de 2004 a 2016 com o objetivo de compreender o que essas produções têm revelado, considerando as concepções de formação de professores e de prática propostas/discutidas nas últimas décadas. Nas produções analisadas, constatamos que o estágio supervisionado e a prática de ensino trazem de forma recorrente a reflexão como fio condutor, e são considerados como um espaço de pesquisa, na perspectiva interdisciplinar e de intervenção/transformação, visando favorecer o conhecimento da realidade do profissional docente, a partir da problematização, teorização, reflexão, intervenção e redimensionamento da ação.

Palavras-Chave: Estágio Supervisionado. Prática de Ensino. Formação de Professores.

\begin{abstract}
In this research, I analyze the academic productions presented at the National Meeting of Didactics and Teaching Practice that took place from 2004 to 2016 with the aim of understanding what these productions have revealed, considering the concepts of teacher training and practice proposed/ discussed in the last decades. In the analyzed productions, we found that the supervised internship and the teaching practice recurrently bring reflection as the guiding thread, and are considered as a space for research, in the interdisciplinary and intervention / transformation perspective, aiming to favor the knowledge of the reality of the professional teacher, from the problematization, theorization, reflection, intervention and resizing of the action.
\end{abstract}

Keywords: Supervised Internship. Teaching Practice. Teacher training.

\section{INTRODUÇÃO}

O estágio supervisionado tem um papel integrador na formação do professor e oferece ao aluno oportunidade de ampliar, discutir, refletir e utilizar os conhecimentos adquiridos durante o curso,

\footnotetext{
${ }^{1}$ Doutora em Ciências da Religião PUC/SP. Professora da Universidade Estadual de Montes Claros - UNIMONTES. E-mail: rosana.joao@yahoo.com.br
} 
na busca por responder as necessidades e os desafios da realidade escolar, objetivando estabelecer uma relação dialógica entre teoria e prática. No estágio, o aluno deverá se aproximar da realidade da sala de aula ou da escola para que a partir dos dados observados e das vivências, neste contexto, seja possível fazer uma reflexão sobre a prática pedagógica que se efetiva na escola. Essa reflexão proporcionará informações que certamente complementarão a sua formação:

[...] a prática da reflexão sobre a prática tem favorecido as discussões sobre o processo pedagógico, suas multifaces e suas questões necessárias indagam a respeito de quem toma as decisões sobre o rumo do processo pedagógico e quais os interesses dos que participam dessas decisões. (...) Todos têm voz e vez para interferir na direção que o projeto do curso vai assumindo. (PICONEZ, 1994, pp. 28-29).

O estágio vai além de uma encenação, de uma situação de mera avaliação no processo de formação, pois pode possibilitar aos estudantes/estagiários a realização de uma atividade teórico-prática, críticareflexiva sobre a docência, respaldada pelo referencial teórico e pelo conhecimento de uma realidade de atuação, devendo articular ensino, pesquisa e extensão.

Cury (2003, pp. 113-122) refere-se ao Estágio Curricular Supervisionado como a oportunidade de articulação entre o momento do saber e o momento do fazer, ao afirmar que: "O momento do saber não está separado do momento do fazer, e vice-versa, mas cada qual guarda sua própria dimensão epistemológica". O aprender a ser professor, dessa forma, é reconhecido como um "saber profissional intencionado a uma ação docente nos sistemas de ensino". Almeida e Pimenta (2014, p. 73) afirmam que o professor que recebe o estagiário:

[...] também é um formador de professores e responsável pela construção da identidade docente do estudante, pois este compartilha saberes construídos a partir de suas vivências profissionais dentro de um contexto sócio histórico e técnicopedagógico

Sendo assim, o estágio supervisionado é um componente curricular abrangente no qual os alunos estagiários vivenciarão práticas e modos de atuação do cotidiano escolar, pois, conforme disposto no artigo 13 da Lei de Diretrizes e Bases da Educação Nacional (LDBEN/96), os alunos não poderão ser visualizados meramente como profissionais que atuarão somente na sala de aula, devendo participar da vida da escola de um modo geral, o que inclui a sua participação em atividades tais como elaboração da proposta pedagógica da escola, elaboração e cumprimento de planos de trabalho, zelo pela aprendizagem do aluno, estabelecimento de estratégias de recuperação para alunos de menor 
rendimento, participação nos períodos de planejamento, avaliação e desenvolvimento profissional, colaboração com as atividades de articulação da escola, com as famílias e a comunidade.

Compreendido dessa forma, o estágio supervisionado não deve ser de responsabilidade somente de uma disciplina-campo de saber como, a Didática e a Prática de Ensino. Por isso, se faz necessário que as diferentes disciplinas que compõem os currículos dos cursos de formação de professores busquem estratégias/metodologias de interação, que subsidiem os estagiários e lhes deem a possibilidade de elaborar conceitos, interpretar e reconhecer a realidade. Desse modo, a relação teoria-prática pode ser construída. Para tanto, a proposição de estágios nos cursos de licenciatura deve se constituir em um projeto integrador, construído pelos responsáveis pela oferta das disciplinas do curso, a partir da identificação e análise das principais questões comuns ao cotidiano escolar.

Nessa perspectiva, o estágio curricular obrigatório funcionará como elo entre os componentes curriculares da formação comum (conhecimentos sobre o aluno nas suas diferentes dimensões, sobre a escola básica, sobre a dimensão cultural, social, ambiental, política e econômica da educação e conhecimentos pedagógicos) e os da formação específica (conhecimentos que são objeto de ensino), garantindo a inserção do licenciando na realidade viva do contexto escolar.

É necessário, para tal, que os envolvidos na oferta do curso tenham clareza quanto ao perfil de profissional que buscam formar, para que direcionem seus esforços, nesse sentido. $\mathrm{O}$ estágio/prática do curso deveria constituir-se em espaços/tempos importantes de formação, oportunizadores de sínteses pessoais sobre conteúdos, teorias e experiências.

Lembramos que o estágio supervisionado se constituiu por muito tempo como a única disciplina de prática de ensino dedicada a orientar a formação de futuros professores nos cursos de licenciatura. Porém, a legislação da última década introduziu novas formas de conceber a prática de ensino nas licenciaturas, considerando a necessidade de maior integração entre teoria-prática na formação inicial. Neste sentido, introduziu a inserção de práticas, desde o início dos cursos de licenciaturas, mobilizando e articulando diferentes conhecimentos e experiências.

O acadêmico deverá, de acordo com essas novas propostas, ao longo de toda a sua formação, vivenciar situações próprias do ambiente escolar, procurando articular os conhecimentos adquiridos das diferentes disciplinas cursadas, de maneira que esses lhes permitam enfrentar os desafios, encontrar novas saídas e fazer avançar os processos de ensino-aprendizagem.

Dessa forma, teoria e prática passam a ser consideradas indissociáveis da ação docente, uma vez que, para refletir a respeito das dificuldades, necessidades, contradições que 
emergem da prática, é preciso buscar as teorias. Segundo Pimenta e Lima (2004), as teorias exercem um papel fundamental na ressignificação da prática, pois iluminam e oferecem instrumentos necessários de análise e investigação, através dos quais é possível questionar práticas institucionalizadas e as ações dos sujeitos e, ao mesmo tempo, rever as próprias teorias.

É importante que os estágios valorizem as atividades que proporcionam um aprender a aprender e um saber pensar, raciocinar, investigar, tendo como foco o desenvolvimento de habilidades e competências, pois, pela dinâmica e rapidez cada vez maior com que os saberes são produzidos, as metodologias deverão proporcionar autonomia ao acesso do conhecimento.

O estágio na formação do educador, dependendo da forma como será conduzido, terá um papel formativo fundamental, pois aproxima os estagiários da realidade das escolas, a fim de que eles possam compreender melhor os desafios que deverão enfrentar no mundo do trabalho, de forma crítica e consciente.

Conforme Kulcsar (1994, p. 65), “o Estágio não pode ser encarado como uma tarefa burocrática a ser cumprida formalmente. [...] Deve, sim, assumir a sua função prática, revisada numa dimensão mais dinâmica, profissional, produtora, de troca de serviços e de possibilidades de abertura para mudanças".

Ainda que a importância do estágio seja inegável no processo de formação profissional e que venha sendo objeto de muitas pesquisas e publicações, não percebemos, em nossa realidade, como resultado desses estudos, um impacto significativo na sua dinâmica, em outras palavras, na forma dele ser concebido e desenvolvido no processo de formação inicial de professores. Assim, várias questões têm nos instigado com relação a essa problemática, tais como: O que esses estudos em outros espaços têm mostrado? Quais são as concepções de prática de ensino e de estágio supervisionado subjacentes aos aspectos legais tratados? Quais são os limites/desafios e possibilidades apontadas por estes trabalhos? Nesse estudo passamos a refletir pontualmente sobre a prática e estágio no contexto da pesquisa.

\section{A prática e o contexto da pesquisa}

Uma forte tendência presente nos estudos analisados sobre a prática de ensino e o estágio supervisionado e sua relação com a formação docente é a pesquisa. No Brasil, na década de 90, com questionamentos sobre a indissociabilidade entre teoria e prática, no contexto da concepção de professor pesquisador de sua prática, tem origem o movimento de valorização da pesquisa: 
A formulação do estágio como atividade teórica instrumentalizadora da práxis, tendo por base a concepção do professor (ou futuro professor) como intelectual em processo de formação e a educação como um processo dialético de desenvolvimento do homem historicamente situado, abriu espaço para um início de compreensão do estágio como uma investigação das práticas pedagógicas nas instituições educativas. (PIMENTA e LIMA, 2004, p. 47).

Assim, com as contribuições de autores sobre a concepção do professor como profissional reflexivo, o estágio passa a ser visto também como facilitador da articulação teoria e prática, possibilitando ao licenciando o desenvolvimento de "[...] comportamentos de observação, reflexão crítica, reorganização das ações, características próximas à postura de um pesquisador, investigador, capaz de refletir e reorientar sua própria prática, quando necessário". (KENSKI, 1994, p. 47).

De acordo com Barcelos (2006, p.74), as novas diretrizes sobre Formação de Professores para a Educação Básica:

Convocam os formadores de professores a refletirem sobre dois aspectos: tornar a formação inicial de professores um efetivo projeto coletivo, capaz de envolver a instituição formadora e o conjunto de formadores, e estabelecer uma parceria com a escola, na qual estagiários, professores e supervisores de estágio, juntos, possam aprender a trabalhar profissionalmente no cotidiano escolar.

Desde então, inúmeros pesquisadores defendem a introdução da pesquisa nos cursos de formação de professores. Trabalhos, como o de Gil-Pérez e Carvalho (2000), consideram a iniciação do licenciando à pesquisa como requisito básico para sua formação, pois associando ensino e pesquisa às necessidades formativas do graduando, estas se complementariam na utilização da pesquisa para inovações didáticas dentro de sua futura prática.

Dentre outras experiências que buscam colocar a dimensão da pesquisa no processo formativo dos professores, aparecem os trabalhos de Bastos e Caldeira (2000), que fizeram esforços para compatibilizar os estágios de observação/regência com pequenos projetos de pesquisa, já Galiazzi e Moraes (2001) investigaram experiências sobre a utilização da pesquisa como princípio didático em cursos de licenciatura.

Tardif (2000) relata inúmeras experiências e possibilidades na formação inicial em diferentes países, em mais de duas décadas, que utilizam a colaboração dos professores da escola, como co-pesquisadores na reelaboração do repertório de conhecimentos para o ensino.

Fazenda (1991) insiste na necessidade de se ter um projeto coletivo de formação do educador e nele contemplar o lugar do estágio; ainda, segundo essa autora, urge entender o estágio na perspectiva da pesquisa. Ludke (2001, p.127) pergunta: “Até que ponto a dimensão 
da pesquisa constitui preocupação efetiva dos currículos dessas instituições ao preparar o futuro professor?” Kenski (1994), por sua vez, observa que a vivência escolar dos estágios pode ser aproveitada como ponto inicial de pesquisa em atividades desenvolvidas no próprio estágio.

Ghedin (2008), norteando-se pela questão - Qual é o papel da pesquisa na formação do professor no espaço do estágio enquanto práxis formativa? Busca fundamentar epistemologicamente e metodologicamente o desenvolvimento de práticas formativas centradas na produção do conhecimento, a partir da pesquisa, e conclui, ainda, parcialmente que:

O trabalho docente implica a mobilização de um conjunto de saberes e, dentre estes, o saber produzir conhecimento com autonomia, propriedade científica, sistematicidade e rigor, ações e condições que não são possíveis sem a aprendizagem da investigação como instrumento que possibilita a transformação da experiência em conhecimento sistematizado. (GHEDIN, ALMEIDA, 2008, p. 10).

O enfoque do ensino voltado para o desenvolvimento da capacidade reflexiva do futuro professor direciona o processo de formação docente para um processo de pesquisa, capaz de formar um professor pesquisador. Pimenta (2002) reflete sobre alguns aspectos deste enfoque, partindo do pressuposto que a pesquisa é um instrumento valioso na formação docente. Nesse sentido, a autora traz alguns questionamentos: "que tipo de reflexão tem sido realizada pelos professores? As reflexões incorporam um processo de consciência das implicações sociais, econômicas e políticas da atividade de ensinar? Que condições têm os professores para refletir?”. (PIMENTA, 2002, p. 25).

Pimenta entende que o estágio supervisionado deve se constituir em uma possibilidade concreta de problematização da prática pedagógica, que a relação teoria e prática pode ser equacionada através da pesquisa. Pimenta e Lima (2004, p. 23) propõem “o estágio realizado com pesquisa e como pesquisa contribuindo para uma formação de melhor qualidade de professores". Segundo as autoras, é necessário que a pesquisa realizada no estágio não se configure como uma pesquisa que não seja do estagiário. Por isso, torna-se necessário compreender o estágio com e como pesquisa bem como sua importância na formação docente dos futuros professores, o que leva a questionar o aligeiramento dessa formação, o que pode ser um empecilho a essas propostas. Essa proposta baseia-se em pesquisas que apontam:

Com unanimidade, que a universidade é por excelência o espaço formativo da docência, uma vez que não é simples formar para o exercício da docência de qualidade e que a pesquisa é o caminho metodológico para essa formação. Contrapõem-se, portanto, às orientações das políticas geradas a 
partir do Banco Mundial, que reduzem a formação a mero treinamento de habilidades e competências. (PIMENTA e LIMA, 2004, p. 41).

De acordo Barreiro e Gebran (2006, p.24), a pesquisa provoca no acadêmico "a incerteza, ou seja, a desestruturação de suas verdades, pois enfrentar uma situação concreta que precisa ser refletida, não pode ser buscada simplesmente na reprodução de idéias". Esse processo caracteriza-se pela busca de soluções para os problemas detectados, exigindo reflexão e nova ação. Para isto, é essencial a relação teoria e prática.

Nesta mesma linha, Lins (2004), no trabalho intitulado A articulação teoria-prática: o papel da pesquisa na formação profissional destaca que a pesquisa provoca uma desconstrução, no sentido de colocar as teorias à prova e não as aceitar como dogmas, o que acarretaria uma postura profissional improdutiva.

No que diz respeito ao ato de pesquisar, os alunos, aos poucos, desconstroem a idéia que fazem de que para pesquisar é necessário apenas se apropriar de técnicas e passam a compreender este processo como um processo que exige capacidade de observação, questionamento, análise, reflexão, critica, articulação de pensamento (teoria - realidade, Psicologia - outras áreas de conhecimento), enfim, criação. É possível visualizar, também, o processo de aquisição de autonomia intelectual do aluno em relação às idéias defendidas pelo professor, uma vez que ele entra em contato com uma referência bibliográfica construída a partir das necessidades de seu objeto de estudo e de suas identificações com as idéias discutidas pelos autores lidos; cria-se, neste sentido, clima favorável ao questionamento, à dúvida, essenciais para processo de conhecimento. (LINS, 2016, p. 04)

Neste sentido, Pimenta e Lima (2004, p. 43) defendem:

[...] o papel das teorias é iluminar e oferecer instrumentos e esquemas para análise e investigação que permitam questionar as práticas institucionalizadas e as ações dos sujeitos e, ao mesmo tempo, colocar elas próprias em questionamento, uma vez que as teorias são explicações sempre provisórias da realidade.

Porém, o processo de acesso à teorização da prática só é possível por um processo de reorganização interpretativa do fazer, à luz de outras interpretações a respeito da realidade. Deste modo, podemos dizer que a teoria tem importância fundamental na formação dos docentes, pois dota os sujeitos de variados pontos de vista para uma ação contextualizada, oferecendo perspectivas de análise para que os professores compreendam os contextos históricos, sociais, culturais, organizacionais e de si próprios como profissionais.

Desse ponto de vista, pesquisa no estágio pode possibilitar ao acadêmico desenvolver posturas e habilidades de investigação, buscando elaborar projetos que propiciem situações para compreender e problematizar a realidade vivida. Segundo Moraes (2000, p. 112): 
A perspectiva de realização da pesquisa nos estágios supervisionados indica uma mudança no processo de realização dessa atividade. Ao invés de esses trabalhos tomarem o esquema observação, participação e regência, verificou-se neles a utilização da metodologia da pesquisa (grifo da autora), ou seja, a realização dos estágios por meio das seguintes fases: identificação das dificuldades que envolvem o cotidiano escolar (problematização), seleção do referencial teórico, elaboração de um projeto - ação, aplicação desse projeto (intervenção) e análise dos resultados

A perspectiva trazida por Moraes (2000) aponta para a realização do estágio como pesquisa, em que se levanta uma problemática, ou seja, uma dificuldade busca-se um referencial teórico e elabora-se um projeto. Esse inclui a definição de objetivos, da metodologia e dos procedimentos metodológicos. Em seguida, executa-se o projeto, analisamse os resultados e produz-se um relatório. É nesse aspecto que "o estágio como pesquisa, se coloca agora, como postura teórico-metodológica e desafio". (PIMENTA; LIMA, 2004, p. 56).

Há pesquisadores brasileiros, envolvidos com a temática da prática e do estágio, que desenvolvem seus trabalhos neste campo na perspectiva da pesquisa como elemento que possibilita a articulação entre teoria e prática, tanto no desenvolvimento profissional quanto curricular. Dentre eles, Lima e Pimenta, citadas anteriormente, como também Evandro Ghedin que apresentaram trabalhos tratando do tema, tanto no ENDIPE 2004, como 2008, defendendo o estágio como pesquisa.

Ghedin (2004), no trabalho intitulado A pesquisa como eixo interdisciplinar no estágio e a formação do professor pesquisador-reflexivo, alerta para o cuidado que a universidade deve ter para além da formação voltada para o ensino, exigindo uma reformulação da concepção curricular:

Dentro desta perspectiva destacam-se algumas propostas que estimulam uma revisão na formação acadêmica dos professores: o professor investigador em aula e o professor pesquisador. No âmbito da formação especificamente acadêmica a perspectiva do professor/pesquisador traz algumas implicações que obrigam a uma revisão do processo formativo e da concepção curricular. Uma dessas implicações diz respeito às formas de superação do tradicional distanciamento entre pesquisa acadêmica e prática pedagógica. Nessa direção compreendemos que a prática reflexiva tem o mesmo sentido e direção da prática orientada pela pesquisa. (GHEDIN, 2004, p. 675).

No trabalho apresentado em 2008, Ghedin e Almeida, buscando responder à questão qual é o papel da pesquisa na formação do professor no espaço do estágio enquanto práxis formativa-, concluem que o estudante durante a formação inicial deve ter a oportunidade de 
aprender a produzir conhecimento com rigor, o que certamente será possível com práticas investigativas:

Dentro do contexto e dos limites deste trabalho, podemos concluir que este texto nos leva a pensar, enquanto conclusão parcial, até aqui possível, que o trabalho docente implica a mobilização de um conjunto de saberes e, dentre estes, o saber produzir conhecimento com autonomia, propriedade científica, sistematicidade e rigor, constituem-se ações e condições que não são possíveis sem a aprendizagem da investigação como instrumento que possibilita a transformação da experiência em conhecimento sistematizado. Isso quer dizer que não é possível continuar ensinando a aprendizagem da profissão sem ensinar junto com ela os processos que permitem ao professor iniciante dominar os meios para produzir os produtos e as próprias condições de seu trabalho enquanto intelectual crítico. (GHEDIN; ALMEIDA, 2008, p. $10)$.

Assumir o estágio como prática orientada pela pesquisa, pode ser uma maneira para criar condições para o surgimento de atitudes mais interdisciplinares. Esta dinâmica torna-se possível, quando o Estágio constitui-se em oportunidade coletiva para elaboração do conhecimento sobre a prática, além de ser espaço de reelaboração de saberes que se processam na prática de ensino.

Mattei e Malanchen (2004) relatam a realização de um trabalho na Prática de Ensino do curso de Pedagogia como pesquisa:

Buscando na disciplina a unidade entre teoria e prática, considerando as contradições e conflitos ideológicos existentes. Partindo dessa discussão, foi realizada uma pesquisa do tipo etnográfica e análise do projeto político pedagógico da escola campo. Para concluir esta pesquisa, foram propostos possíveis projetos para serem desenvolvidos na prática de ensino II. (MATTEI; MALANCHEN, 2004, p. 1211).

Também Dorneles e um grupo de alunos (2006) desenvolvem a disciplina Prática de Ensino II no curso de Educação Física da UNIJUÍ, utilizando a investigação como estratégia para analisar as ações realizadas pelo professor de Educação Física, bem como, diagnosticar a visão da direção das escolas sobre o desempenho do professor de Educação Física no contexto escolar.

A transformação da prática dos professores se dá, pois, numa perspectiva crítica. Assim, deve ser adotada uma postura cautelosa na abordagem da prática reflexiva, conforme já abordamos anteriormente, evitando que a ênfase no professor não venha a operar, estranhamente, a separação de sua prática do contexto organizacional no qual ocorre. Fica, portanto, evidenciada a necessidade da realização de uma articulação, no âmbito das investigações sobre prática docente reflexiva, entre práticas cotidianas e contextos mais 
amplos, considerando o ensino como prática social concreta. Essa articulação, em nosso entender, só pode dar-se por um processo de investigação. "Por isso é fundamental que os professores, já no seu processo de formação inicial, possam fazer uma experiência de pesquisa. Pensamos que o estágio constitui-se um tempo e um espaço privilegiado para este processo formativo" (GHEDIN 2004, p. 683).

Lemos (2008) também toma a prática de ensino e o estágio como objeto de pesquisa, investigando as bases teóricas e metodológicas que fundamentam a disciplina Pesquisa e Prática Pedagógica e os seus desdobramentos, analisando as suas ementas e programas e comparando-as com o documento de implementação da proposta. Esses autores concluem que, embora a proposta seja inovadora, o trabalho interdisciplinar e coletivo ainda necessita de maior cuidado.

As aproximações referem-se à organização da estrutura das disciplinas e os distanciamentos referem-se a sua dinâmica. $\mathrm{O}$ documento propositivo para a prática de ensino em forma de Pesquisa e Prática Pedagógica, e a proposta implementada no Centro de Educação da UFPE se caracterizam como inovadores. Entretanto, a perspectiva interdisciplinar que perpassa a proposta, ainda requer muito esforço para a sua construção, assim como o trabalho coletivo. (LEMOS, 2008, p. 01).

O estágio é também considerado objeto de estudo no trabalho de Ramos e Wense (2016), em que buscam identificar a percepção de professores-regentes sobre o estágio supervisionado do curso de História da Universidade Estadual de Santa Cruz e indicam que:

Os resultados revelaram que o estágio do curso de História vem sendo desenvolvido sem a articulação necessária de existir entre a agência formadora e as escolas campo. Quanto ao desempenho dos estagiários, os regentes indicaram que estes apresentam bom conhecimento do conteúdo, mas enfrentam dificuldades de relacionamento com os alunos e poucas inovações pedagógicas. (RAMOS; WENSE, 2016, p. 01).

Campos (2008), em uma síntese de sua tese de doutorado, toma a prática de ensino como objeto de estudo, buscando atribuir-lhe um novo significado, a partir do que propõe as Diretrizes Curriculares e os teóricos da prática reflexiva e conclui que:

[...] não se promove a articulação da prática e teoria enquanto eixo do currículo, mas apenas em algumas disciplinas isoladas. Em face disso, é possível dizer que o panorama desfavorece uma profissionalidade que ressalta o papel de professor como alguém atuante, crítico, criativo e comprometido com as finalidades educacionais na educação básica, distanciando-se da perspectiva de profissionalização docente.

Oitocentas (800) horas de prática nos cursos: restrita à prática de ensino e estágio curricular; oferecimento nas disciplinas de cunho pedagógico e de 
forma isolada no currículo; articulação Teoria e Prática é "apêndice" não eixo curricular. (CAMPOS, 2008, p. 01).

Essa conclusão de Campos aponta para o fato de que a prática, ao ser considerada um componente curricular com uma carga horária determinada, caracterizada e desenvolvida como prática de ensino e estágio, deixa de ser um elemento constituinte de todas as disciplinas do curso, o que seria fundamental para uma formação em que todos estivessem imbuídos do objetivo principal que é a formação do professor para atuar na educação básica. Conforme afirma a autora, essa prática está distante da defendida no referencial teórico por ela adotado.

Sousa (2008, p. 01) traz um estudo em que investigou fatos históricos relevantes que contextualizam a dimensão prática da formação no estágio supervisionado, e conclui:

[...] o Estágio se apresenta no contexto histórico, como um aspecto relevante na dimensão prática da formação, sendo um espaço de reflexão, possibilitando transformações na prática profissional, além de apresentar como finalidade a articulação das diferentes práticas, numa perspectiva interdisciplinar.

Borges (2004), partindo dos relatórios finais das disciplinas: Prática em Orientação Educacional e Estágio Supervisionado em Orientação Educacional e do desenvolvimento de grupos de discussão mediados pela professora em sala de aula, constatou a ausência de espaços acadêmicos que tratassem de situações inusitadas, transformando esses dados em elementos de análise, formulando as seguintes questões:

[...] até que ponto o inusitado permite desvelar os limites e possibilidades do processo de formação do Orientador Educacional? Esta questão central se desdobra nos três objetivos da pesquisa: 1) Conceituar as situações inusitadas advindas do campo de estágio; 2) Analisar as faces das situações inusitadas apresentadas e discutidas com os alunos; 3) Propor alguns encaminhamentos frente às situações inusitadas evidenciadas pelos estagiários. (BORGES, 2004, p. 3628).

Souza e o seu grupo de pesquisa (2006) apresentaram um trabalho que também toma o estágio na licenciatura em Biologia como objeto de pesquisa com o seguinte objetivo:

[...] entender a complexidade de sentidos construídos sobre o estágio e as condições de produção dos estágios curriculares da licenciatura em Biologia. Procurando levantar a problemática integração universidade e escola, a partir de seus atores, procuramos analisar numa fase exploratória, os documentos sobre tema, como os Projetos Pedagógicos de escolas que já eram nossos campos de estágio, manuais de estágio, entre outros. Também observamos a 
fala de vários sujeitos envolvidos no funcionamento dos estágios: diretores, professores e estagiários [...]. (SOUZA et al, 2016, p. 01).

Outro estudo na mesma linha é o de Almeida (2006 p. 01), cujo objetivo foi o de avaliar o processo de realização do estágio acadêmico no curso de Administração na IES “ $X$ ” e sua importância para a formação técnica e humana do futuro profissional.

Na pesquisa apresentada por Carvalho (2006), a pesquisadora tomou como sujeitos professores e alunos do estágio, buscando investigar como a compreensão sobre o papel do estágio em sua formação inicial é construída. Assim, o estágio é objeto de pesquisa. Nas considerações provisórias, a autora afirma:

[...] apresentamos as impressões iniciais refletindo sobre a superação do reducionismo teoria-prática que esta disciplina foi renegada ao longo da história dos cursos de licenciaturas, na perspectiva de re-significação do papel do estágio, a academia e o espaço para a subjetividade, as possibilidades e potencialidades formativas oferecidas pelas vivências na abordagem (auto) biográfica, construindo diferentes percursos formativos, para além das competências; por uma outra epistemologia da formação. (CARVALHO, 2008, p. 01).

Maria do Socorro Lima apresenta em 2004 um estudo das produções dos ENDIPEs, de 2000 a 2002, analisando as contribuições dos estudos e pesquisas apresentadas para o estágio supervisionado. Entendemos que, nesse trabalho, o estágio passa a ser um objeto de pesquisa, assim caracterizado pela autora:

O objetivo deste trabalho é refletir sobre a contribuição desses encontros para a produção do conhecimento no estágio curricular, realizado nos cursos de formação docente, e analisar as tendências teorias e práticas dos trabalhos apresentados nos pôsteres e painéis publicados nos Anais dos X e XI ENDIPEs. Para identificar as tendências investigativas e as práticas dos professores no Estágio Supervisionado, realizou-se uma investigação que consistiu em analisar os dois eventos em um só bloco de 149 pôsteres e painéis, considerando-se os trabalhos teóricos sobre os vinte anos de ENDIPE, bem como as publicações sobre as Práticas de Ensino das disciplinas específicas. (LIMA, 2004, p.30).

Nessa perspectiva Lima (2012, p. 138) pontua o Endipe “[...] é um evento de caráter científico, situado no campo educacional, que reúne profissionais e pesquisadores de diferentes instituições em torno de questões relacionadas aos processos de ensino e aprendizagem. Nesse estudo, a autora chega às seguintes conclusões, destacando que nos trabalhos analisados prevalece o processo investigativo: 
Dessa forma, verifica-se, ainda, que o enfrentamento dos desafios, problemas e a avaliação do ensino superior no contexto das reformas políticas e educacionais encontram, no Estágio Supervisionado curricular, espaço para discussão, debate e troca de experiências. Finalizando, percebese que, nos painéis e pôsteres analisados, prevaleceu o processo investigativo, tanto como objeto de análise de pesquisas, como em atividade da disciplina ou integrando o conjunto de trabalhos realizados (...).

Incluem-se, ainda, as pesquisas que se utilizam do material produzido no Estágio e o seu próprio desenvolvimento no currículo das licenciaturas. A pesquisa bibliográfica sobre os fundamentos e do estudo conceitual destacase na quase totalidade dos registros, principalmente nos painéis (...).

É preciso ter cuidado para que os reais objetivos do estágio curricular não se percam com o maior uso de procedimentos de pesquisa no decorrer do estágio. É necessário que a pesquisa, realizada no estágio, não se configure como uma pesquisa que não seja do estagiário. Por isso, torna-se necessário compreender o estágio com e como pesquisa bem com sua importância na formação docente dos futuros professores. (LIMA, 2004, p. 3058).

Essa mesma autora, em 2008, apresentou um trabalho intitulado O estágio como aprendizagem da profissão, mediado pela pesquisa, em que, relatando um projeto desenvolvido em cursos de licenciaturas por quatro professores, destaca o papel da Didática e da pesquisa como elemento mediador e articulador no processo de formação docente:

O papel da Didática é fundamental para que os cursos de licenciatura promovam a reflexão sobre a docência, tendo a prática como ponto de chegada e de partida. Acreditamos que pesquisa no Estágio/Prática de Ensino pode fazer essa mediação e articular o diálogo necessário para a formação docente. (LIMA, 2008, p. 09).

Azevedo e Abib (2006, p. 01), também tomam as produções apresentadas nos ENDIPEs com o objetivo de:

Focar as pesquisas apresentadas nos três últimos Encontros Nacionais de Didática e Prática de Ensino, quanto à forma de desenvolvimento dos estágios supervisionados em relação aos estilos de orientação/supervisão empreendidos pelos professores formadores junto aos estagiários.

o processo investigativo no estágio supervisionado e na prática de ensino ainda se faz presente de forma marcante, nas produções por nós analisadas, quer considerando-os como objeto de pesquisa, ou usando a pesquisa como estratégia para o seu desenvolvimento. Especialmente, em 2008,2012 chama-nos a atenção que vários foram os trabalhos que consideram o estágio como objeto de pesquisa. Isso nos leva a inferir que os pesquisadores estão sentindo a necessidade de se debruçarem sobre essa temática, buscando investigar os avanços que os aspectos legais, as teorias e as experiências têm trazido a esse importante componente da formação, como também investigar o que ainda tem se constituído em 
obstáculo ou em limites para que a prática assuma o seu papel. Enfim, verificar em que medida e aspectos estamos nos aproximando ou nos afastando do discurso de uma prática reflexiva e transformadora que tem sido a tônica dos discursos que a sustenta nos últimos anos. , ou seja, problematizar a própria prática.

A seguir pontuamos outros aspectos revelados pelas produções apresentadas nos ENDIPEs estudados que julgamos relevantes:

- O estágio supervisionado e a prática são considerados um espaço interdisciplinar de formação, com a finalidade de favorecer maior conhecimento da realidade profissional, através de um processo de estudo, análise, problematização, teorização, reflexão, proposição de alternativas, intervenção e redimensionamento da ação;

- As práticas interdisciplinares não têm um sentido único. Sob esta perspectiva, alguns trabalhos concebem a prática de ensino e o estágio como espaços propícios para a articulação entre conteúdo específicos e conteúdos pedagógicos, outros atribuem a eles o papel de integração do contexto profissional ao contexto formativo, e outros ainda como espaço de integração entre a prática e a teoria;

- A pesquisa de cunho interdisciplinar é apresentada como uma alternativa para as mudanças nas práticas dos cursos de formação de professores, considerando que é a partir do contato real com o trabalho pedagógico, que os alunos e professores podem reconhecer a insuficiência do conhecimento, ou seja, problematizar a própria prática;

- A prática de ensino vivenciada no estágio com o objetivo de formar um professor reflexivo, crítico e pesquisador aparece como uma possibilidade promissora para que o aprendizado da profissão se dê numa construção coletiva, em que todas as dimensões possam ser exploradas. Destacam, ainda, que a postura do estagiário é um fator determinante para que esse objetivo possa ser atingido;

- A prática de ensino e o estágio são considerados como momentos privilegiados de ação-reflexão-ação, e como elementos integradores do currículo, que possibilitam a unidade teoria-prática;

- O estágio é enfatizado como possibilidade de intervenção/transformação. Essas produções deixam transparecer, de forma explícita, que os projetos devem acontecer de forma conjunta entre as escolas de formação e as escolas-campo, entre seus professores, alunos e coordenadores, deixando clara a preocupação 
de que a instituição formadora deve elaborar os projetos a partir das problemáticas levantadas na realidade escolar e/ou na sala de aula, podendo assim promover mudanças;

- O estágio é também apontado como um espaço de formação continuada do professor que recebe o estagiário, e, entre eles, pode-se estabelecer um momento rico de trocas em que ambos têm a oportunidade de aprender e de se constituir como professor;

- Alguns estudos apresentados enfatizam a importância da articulação entre a instituição formadora e a escola-campo, embora essa articulação seja ainda um aspecto complexo com dificuldades para ambas. Há produções que apresentam experiências exitosas nesse sentido, embora a falta de articulação entre universidade tenha sido apontada como algo que vem gerando dificuldades para os futuros professores construírem os saberes relativos à prática escolar;

- O estágio tem deixado de ser apenas preocupação do professor de didática ou do professor orientador, embora os estudos relatem a necessidade de envolvimento de todos os formadores;

- Os instrumentos de registro, como relatórios, portfólios, diários de campo têm se constituído em elementos importantes de formação, de construção de saberes, de reflexão, assim como têm sido objeto de estudo.

As produções nos revelaram desafios, dentre eles, destacamos a necessidade de:

- Ampliar espaços de diálogos entre universidade, escola e comunidade;

- Promover a indissociabilidade entre ensino, pesquisa e extensão, garantindo a qualidade da formação inicial;

- Entender o estágio supervisionado e a prática como componentes integrantes do currículo;

- Promover condições para que o professor orientador de estágio coordene e acompanhe efetivamente o estágio na escola campo;

- Promover uma maior participação e compromisso dos formadores com as questões e demandas que a escola básica coloca aos estagiários;

- Não restringir a responsabilidade da prática de ensino somente ao professor orientador do estágio, mas a todos os professores formadores.

As produções nos revelaram também possibilidades, dentre as quais destacamos: 
- o fortalecimento da relação da instituição de ensino superior e as escolas de educação básica, constituindo grupos de estudo, de planejamento, de avaliação, por meio do trabalho coletivo, do trabalho colaborativo, da pesquisa-ação;

- a abertura para o diálogo entre formadores e entre esses e a comunidade;

- a formação do professor como um investigador de sua prática, capaz de refletir na ação e sobre a ação;

- o aproveitamento das produções dos alunos no estágio, como instrumento de formação, de discussão para os formadores e gestores.

\section{Considerações Finais}

Os estudos assinalaram que os problemas e desafios são grandes, complexos e múltiplos, mas existem várias iniciativas buscando propostas de estágios que sejam coerentes com os princípios norteadores da formação de professores, observa-se, entretanto, que estas propostas estão em um processo de construção, mesmo que apresentem resultados significativos. Acreditamos que as análises aqui apresentadas possam contribuir de forma significativa para ampliar as discussões quanto ao desenvolvimento da prática e do estágio supervisionado nas universidades, para a elaboração de novas estratégias para uma formação inicial de professores, consistente e eficaz.

\section{Referências}

ALMEIDA, Liliane Regis de. O papel dos estágios acadêmicos na formação profissional do administrador: estudo de caso na instituição de ensino superior " $X$ ". In: XIII ENDIPE ENCONTRO NACIONAL DE DIDÁTICA E PRÁTICA DE ENSINO, 2006, Recife. Educação, questões pedagógicas e processos formativos: compromisso com a inclusão social, Anais Eletrônicos, 2006.

ALMEIDA, M. I. de; PIMENTA, S. G. (Org.). Estágios supervisionados na formação docente: educação básica e educação de jovens e adultos. São Paulo: Cortez, 2014. 156 p.

AZEVEDO, Maria Antônia Ramos de; ABID, Maria Lucia Vital dos Santos. Os estágios supervisionados e os estilos de Orientação. In: XIII ENDIPE - ENCONTRO NACIONAL DE DIDÁTICA E PRÁTICA DE ENSINO, 2006, Recife. Educação, questões pedagógicas e processos formativos: compromisso com a inclusão social, Anais Eletrônicos, 2006.

BARREIRO, Iraide Marques de Freitas; GEBRAN, Raimunda Abou. Prática de Ensino e Estágio Supervisionado na formação de Professores. São Paulo: Avercamp, 2006.

BORGES, Lívia Freitas Fonseca. Educação Superior: abrindo trilhas para investigar o inusitado no contexto do estágio supervisionado em orientação educacional. In: XII ENDIPE - ENCONTRO NACIONAL DE DIDÁTICA E PRÁTICA DE ENSINO, 2004, 
Curitiba. Conhecimento Local e Conhecimento Universal: Diversidade, Mídias e Tecnologias na Educação, Anais Eletrônicos, 2004.

BRASIL. Lei n. 9.394 , de 20 de dezembro de 1996. Estabelece as diretrizes e bases da educação nacional. Disponível em < http://www.planalto.gov.br/ccivil_03/LEIS/ 19394.htm> Acesso em 10.02.2008.

CAMPOS, M. Z. . A Prática nos cursos de licenciatura: reestruturação da formação inicial. In: ENDIPE - XIV ENCONTRO NACIONAL DE DIDÁTICA E PRÁTICA DE ENSINO, 2008, Porto Alegre. Trajetórias e processos de ensinar e aprender lugares, memórias e culturas, Anais eletrônicos, 2008.

CARVALHO, Ana Jovina Oliveira Vieira de. Estágio Supervisionado E Narrativas (Auto) Biográficas: experiências de uma outra epistemologia da formação docente. In: ENDIPE XIV ENCONTRO NACIONAL DE DIDÁTICA E PRÁTICA DE ENSINO, 2008, Porto Alegre. Trajetórias e processos de ensinar e aprender lugares, memórias e culturas, Anais eletrônicos, 2008.

CARVAlHO, Anna Maria Pessoa; GIL-PÉREZ, Daniel. Formação de professores de ciências. 4. ed. São Paulo: Cortez, 2000.

CURY, Carlos Roberto Jamil. Estágio Supervisionado na formação docente. In: LISITA, Verbena Moreira; SOUSA, Luciana Freire (org.). Políticas Educacionais, práticas escolares e alternativas de inclusão escolar. Rio de Janeiro: DP\&A, 2003. p. 113-122

DORNELES, Cleia Inês Rigon. et al. O estágio como uma estratégia de investigação das práticas pedagógicas dos alunos do curso de educação física da Inijuí. In: XIII ENDIPE ENCONTRO NACIONAL DE DIDÁTICA E PRÁTICA DE ENSINO, 2006, Recife. Educação, questões pedagógicas e processos formativos: compromisso com a inclusão social, Anais Eletrônicos, 2006.

FAZENDA, Ivani Catarina Arantes. A Prática de ensino e o estágio supervisionado. Campinas: Papirus, 1991.

GALIAZZI, Maria do Carmo. Educar pela pesquisa: ambiente de formação de professores de crianças. Ijuí-RS: Ed. Unijuí, 2003. 288 p.

GHEDIN, Evandro Luiz. Professor Reflexivo: da alienação da técnica à autonomia da crítica. In: PIMENTA, Selma Garrido; GHEDIN, Evandro (org.) Professor reflexivo no Brasil: gênese e crítica de um conceito. 2. ed. São Paulo: Cortez, 2002. p. 129-150.

GHEDIN, Evandro. A pesquisa como eixo interdisciplinar no estágio e a formação do professor pesquisador-reflexivo. In: XII ENDIPE - ENCONTRO NACIONAL DE DIDÁTICA E PRÁTICA DE ENSINO, 2004, Curitiba. Conhecimento Local e Conhecimento Universal: Diversidade, Mídias e Tecnologias na Educação, Anais Eletrônicos, 2004.

GHEDIN, Evandro; ALMEIDA, Whasgthon Aguiar de. O estágio como aprendizagem dos processos de pesquisa. In: ENDIPE - XIV ENCONTRO NACIONAL DE DIDÁTICA E PRÁTICA DE ENSINO, 2008, Porto Alegre. Trajetórias e processos de ensinar e aprender lugares, memórias e culturas, Anais eletrônicos, 2008. 
KENSKI, Ivani Moreira. A vivência escolar dos estagiários e a prática de pesquisa em estágios supervisionados. In: PICONEZ, Stela. Bertholo. (coord.). A prática de ensino e o estágio supervisionado. 9. ed. Campinas: Papirus,1994, p. 39-51.

KULCSAR, Rosa. O Estágio Supervisionado como Atividade Integradora. In: PICONEZ, Stela C. B. (org.) A Prática de Ensino e o Estágio Supervisionado. 2. ed. Campinas-SP: Papirus, 1994.

LEMOS, Ana Raquel Pereira. A prática de ensino sob forma de pesquisa e prática pedagógica no Curso de Pedagogia. . In: XIII ENDIPE - ENCONTRO NACIONAL DE DIDÁTICA E PRÁTICA DE ENSINO, 2006, Recife. Educação, questões pedagógicas e processos formativos: compromisso com a inclusão social, Anais Eletrônicos, 2006.

LIMA, Maria Socorro Lucena Estágio e aprendizagem da profissão docente. Brasília: Liber Livro, 2012. 172 p. (Coleção Formar)

LIMA, Maria Socorro Lucena. A hora da prática: Reflexões sobre pratica de ensino e ação docente. 3. ed. Fortaleza: Ed. Demócrito Rocha, 2004.

LIMA, Maria Socorro Lucena. Reflexões sobre estágio/prática de Ensino na Formação de Professores. Revista Diálogo Educacional, Curitiba, p. 195-205, jan. 2008.

LINS, Carla Acioli. A Articulação Teoria-Prática: o papel da pesquisa na formação profissional. In: XIII ENDIPE - ENCONTRO NACIONAL DE DIDÁTICA E PRÁTICA DE ENSINO, 2006, Recife. Educação, questões pedagógicas e processos formativos: compromisso com a inclusão social, Anais Eletrônicos, 2006.

MATTEI, Andréa Cristina; MALANCHEN, Julia. Prática de Ensino I: subsídios para uma reflexão sobre a estágio supervisionado na formação do professor. In: XII ENDIPE ENCONTRO NACIONAL DE DIDÁTICA E PRÁTICA DE ENSINO, 2004, Curitiba. Conhecimento Local e Conhecimento Universal: Diversidade, Mídias e Tecnologias na Educação, Anais Eletrônicos, 2004.

MORAES, Pereira Gonzaga de Moraes de. A prática de ensino no curso de Pedagogia: um olhar sobre a produção dos ENDIPEs (1994 e 1996). Florianópolis - SC, 2000 Dissertação (Mestrado) Universidade Federal de Santa Catarina-UFSC.

PICONEZ, Stela Conceição Berto (org.) A prática de ensino e o estágio supervisionado. 2.ed. Campinas, SP: Papirus, 1994.

PIMENTA, Selma Garrido (org.) Saberes pedagógicos e atividade docente. 3. ed. São Paulo: Cortez, 2002.

PIMENTA, Selma Garrido; GHEDIN, Evandro (org.) Professor reflexivo no Brasil: gênese e crítica de um conceito. 2. ed. São Paulo: Cortez, 2002. 224 p.

PIMENTA, Selma Garrido; LIMA, Maria Socorro. Estágio e docência. São Paulo: Cortez, 2004.

RAMOS, Rosenaide Pereira dos Reis; Wense Maria Izabel de Oliveira R. O Estágio supervisionado do curso de licenciatura na percepção dos professores-regentes. In: ENDIPE XVIII ENCONTRO NACIONAL DE DIDÁTICA E PRÁTICA DE ENSINO, 2016. 
Didática e prática de ensino no contexto político contemporâneo: cenas da educação brasileira . Mato Grosso. Anais eletrônicos, 2016.

RICHARDSON, Roberto Jarry. Pesquisa social: métodos e técnicas. 3. ed. São Paulo: Atlas, 1999.

SOUZA, Ana Lourdes Lucena de. O Estágio Supervisionado e a Formação do Professor na História da Educação Brasileira. In: ENDIPE - XVIII ENCONTRO NACIONAL DE DIDÁTICA E PRÁTICA DE ENSINO, 2016, Mato Grosso. Prática de ensino no contexto político contemporâneo: cenas da educação brasileira Anais eletrônicos, 2016.

SOUZA, Ana Lourdes Lucena de; Manuela Fonseca Grangeiro e Tânia Maria Rodrigues Lopes. Breve contexto histórico e experiências de estágio. In: XVIII ENDIPE ENCONTRO NACIONAL DE DIDÁTICA E PRÁTICA DE ENSINO, 2006, Recife. Educação, questões pedagógicas e processos formativos: compromisso com a inclusão social, Anais Eletrônicos, 2016.

Artigo recebido em: 22/02/2020. Artigo aceito em: 10/03/2020. 